\title{
Intercostal nerve blockade with liposomal bupivacaine reduces length of stay after video assisted thoracic surgery (VATS) lobectomy
}

\author{
Kian Banks ${ }^{1,2}$, Sora Ely ${ }^{1,2}$, Diana S. Hsu ${ }^{1,2}$, Dana A. Dominguez ${ }^{1,2}$, Rebecca C. Gologorsky ${ }^{1,2}$, Julia Wei ${ }^{3}$, \\ Clara Maxim ${ }^{3}$, Simon K. Ashiku², Ashish R. Patel ${ }^{2}$, Jeffrey B. Velotta ${ }^{2}$ \\ ${ }^{1}$ Department of Surgery, UCSF East Bay, Oakland, CA, USA; ${ }^{2}$ Department of Thoracic Surgery, Kaiser Permanente Northern California, Oakland, \\ CA, USA; ${ }^{3}$ Division of Research, Biostatistical Consulting Unit, Kaiser Permanente Northern California, Oakland, CA, USA \\ Contributions: (I) Conception and design: S Ely, DA Dominguez, RC Gologorsky, SK Ashiku, AR Patel, JB Velotta; (II) Administrative support: JB \\ Velotta; (III) Provision of study materials or patients: S Ely, J Wei, C Maxim, SK Ashiku, AR Patel, JB Velotta; (IV) Collection and assembly of data: \\ K Banks, S Ely, J Wei, C Maxim; (V) Data analysis and interpretation: All authors; (VI) Manuscript writing: All authors; (VII) Final approval of \\ manuscript: All authors. \\ Correspondence to: Kian Banks, MD. Department of Surgery, UCSF East Bay, 1411 E 31st St Oakland, CA 94602, USA. Email: kian.banks@ucsf.edu.
}

Background: Intercostal nerve blockade (INB) for thoracic surgery analgesia has gained popularity in practice, but evidence demonstrating its efficacy remains sparse and inconsistent. We investigated the effect of INB with standard bupivacaine (SB) with epinephrine versus liposomal bupivacaine (LB) versus a mixed solution of the two on postoperative pain control and outcomes in video assisted thoracoscopic lobectomy patients.

Methods: Since 2014, our practice has shifted from using INBs with SB with epinephrine, to LB, to a mix of the two as the central component of multimodal analgesia after video assisted thoracoscopic surgery. The blocks are performed in a standardized fashion under thoracoscopic visualization consecutively from two rib spaces above to two below the outermost incisions. We retrospectively compared all minimally invasive lobectomies performed at our institution between January 2014 and July 2018 by type of local anesthetic used for INB. We examined median length of stay (LOS), opioid utilization, and subjective pain scores [0-10]. Results: Out of 302 minimally invasive lobectomy patients, 34 received SB with epinephrine, 222 received LB alone, and 46 received the mixed solution. LOS was almost a full day shorter in the LB group than in the SB group (34.8 vs. 56.5 hours, $\mathrm{P}=0.01$ ). There was nearly $25 \%$ lower median total morphine equivalent utilization in the mixed solution cohort compared to the LB cohort ( $7.1 \mathrm{mg}, \mathrm{P}=0.02)$. Additionally, IV morphine equivalent utilization was over $50 \%$ lower in the mixed solution group than in the SB with epinephrine group $(-10.0 \mathrm{mg}, \mathrm{P}=0.03)$.

Conclusions: Our study is by far the largest $(\mathrm{N}=302)$ to compare types of local anesthetic used for INB within a uniform case population. The reductions in LOS and opiate utilization observed in our study among patients receiving LB-based formulations were both statistically and clinically significant.

Keywords: Lung; analgesia; pain; thoracoscopy; video assisted thoracic surgery (VATS)

Submitted Oct 02, 2021. Accepted for publication Dec 09, 2021.

doi: $10.21037 /$ jtd-21-1583

View this article at: https://dx.doi.org/10.21037/jtd-21-1583 


\section{Introduction}

Postoperative pain control in thoracic surgery is critically important and may even contribute to decreased morbidity and length of hospital stay. Effective analgesia in these patients should allow earlier mobilization, adequate pulmonary toilet, and, ultimately, improved lung expansion. Inadequately controlled post-operative pain in this population is associated with increased rates of respiratory infections (1). Additionally, early ambulation is associated with a reduction in complications such as deep vein thrombosis and pneumonia, less time spent in the hospital, and lower overall costs $(2,3)$. Reducing duration of hospitalization not only leads to cost-savings, but it has also been identified as an independent predictor of long-term survival in pulmonary resection patients (4).

Thoracic epidurals had previously been the gold standard in pulmonary resection patients. More recently, several studies comparing intercostal nerve blockade (INB) with liposomal bupivacaine (LB) to thoracic epidural infusion in pulmonary resection patients revealed reduced inpatient length of stay (LOS), reported pain scores, total opioid utilization, overall cost, and pulmonary complication rates in the groups receiving LB INB (5-7). However, the type of optimal INB agent has not been thoroughly investigated.

Data comparing LB to standard bupivacaine (SB) in INB among video assisted thoracic surgery (VATS) patients is limited, and results are mixed (8-13). Additionally, the impact of LB INB on pain control is partially limited by its pharmacology. LB has a gradual onset of action and continues to increase in effectiveness beyond 24 hours suggesting that early in the post-operative period, patients do not experience the full effect of the INB (12). Standard release bupivacaine, by contrast, has a shorter onset to peak effect and this effect drops significantly over the first 12-24 hours (12). We conjectured that use of a novel agent combining $\mathrm{LB}$ and $\mathrm{SB}$ with epinephrine (MIX) would take advantage of the peak effects of both anesthetic agents and provide improved pain relief for patients. We hypothesized that among patients undergoing VATS lobectomy, improved pain control due to LB- or MIXbased INBs leads to reduced LOS when compared to SBbased INBs. We present the following article in accordance with the TREND reporting checklist (available at https:// jtd.amegroups.com/article/view/10.21037/jtd-21-1583/rc).

\section{Methods}

\section{Study design}

Our facility has had a stable group of three thoracic surgeons with internally consistent practice patterns since 2014. INB is used for pain control in almost all thoracic surgery cases (with the exception of a very small proportion of open cases that receive epidural catheters). Our practice shifted uniformly over time from using SB to LB and finally to MIX INBs (our current practice), with the changes in practice occurring uniformly within the surgeon group with minimal temporal overlap of local anesthetic used. We therefore compared retrospective historical cohorts of patients undergoing VATS lobectomy at our institution, grouped by which of three types of local anesthetic agent was utilized in the INB: SB with epinephrine, LB, or MIX (a mix of LB and standard release bupivacaine with epinephrine).

The study was conducted in accordance with the Declaration of Helsinki (as revised in 2013). The study was approved by Institutional Review Board of Kaiser Permanente Northern California (IRB: CN-15-2502-H_06) and individual consent for this retrospective analysis was waived.

\section{Study population}

Patients who underwent VATS lobectomy from January 2014 through July 2018 were identified by procedure code search of our operating room databases and verified by chart review. Patients were excluded if they were less than 18 years of age, underwent other major concurrent procedures, were operated on by a visiting surgeon, or required an admission to the intensive care unit (ICU) after surgery. In our practice, $<2 \%$ of lobectomy patients go to the ICU, so these would represent atypical cases. Additionally, in most cases, standard ICU care would preclude study of our outcome variables.

\section{Anesthetic formulations}

In the $\mathrm{SB}$ group, $30 \mathrm{~mL}$ of $0.25 \% \mathrm{SB}$ with epinephrine $(1: 100,000)$ was injected. In the LB group, $266 \mathrm{mg}(20 \mathrm{~mL}$ drug diluted with normal saline to total volume of $30 \mathrm{~mL}$ ) was injected. In the MIX group, the same volume of LB was mixed with $10 \mathrm{~mL}$ of the same SB with epinephrine solution 
as in the SB group, for a total of $30 \mathrm{~mL}$ of mixed solution. This mixture of SB and LB is considered a safe and effective ratio based on a review of compatibility of $L B$ with other drug products (14).

\section{Technique}

INB was uniformly performed percutaneously at the end of each operation under thoracoscopic visualization, prior to chest tube placement. Local anesthetic was injected in equal amounts in each sequential rib space from one above through one below the most superior and inferior port sites $(5 \mathrm{~mL} /$ space). VATS lobectomies were performed via a three-port approach with minimal variability in technique by one of our facility's three board-certified thoracic surgeons assisted by a general surgery resident of any training level.

\section{Perioperative management}

Perioperative management remained consistent during the study period. Our institution did not begin implementing enhanced recovery after surgery (ERAS) pathways until the latter half of 2018, so our study population is uniform in this respect. Preoperatively, our anesthesiologists consistently provide oral acetaminophen with or without gabapentin. Intraoperatively, rather than opioid, our anesthesiologists administer ketamine in addition to the surgeon-performed INB. While in recovery, the anesthesiologists again administer acetaminophen with or without gabapentin and celecoxib. Upon transfer to the floor, we follow a standard protocol as follows: scheduled acetaminophen, scheduled gabapentin, oxycodone as needed, and hydromorphone as needed for breakthrough pain. Patients may also receive non-steroidal anti-inflammatory drugs (NSAIDs) while on the floor pending surgeon preference.

Patients are deemed suitable for discharge when they are able to manage their pain with minimal oral opioid medication, tolerate a normal diet, and perform near to their baseline level of activities of daily living. The decision regarding readiness for discharge is made by the attending surgeon.

\section{Outcomes}

The primary outcome was LOS. This was chosen as a measure of pain control because an improvement in postoperative pain allows patients to meet discharge criteria such as ambulation and activities of daily living sooner. Additionally, it highlights a factor in overall hospital cost, which is important when considering the addition of a potentially costly therapy. Secondary outcomes were opioid medication utilization during hospitalization (assessed as standard morphine equivalents), subjective pain scores, time to ambulation, and return to emergency department (ED) visits. Pain scores were collected from a standard $0-10$ numeric pain scale that is used routinely by all nursing staff at our institution.

\section{Data collection}

All data points collected for analysis were extracted from the electronic medical record, either electronically by study programmer or by surgeon chart review. Comorbidities were electronically extracted. Specifically, chronic obstructive pulmonary disease is listed as a diagnosis in the patient's chart only after a primary care physician or pulmonologist has verified the diagnosis based on symptoms and pulmonary function testing. Date and time of hospital admission was subtracted from date and time of discharge to calculate LOS. The specific lobe resected was extracted from the operative notes. Pain scores and time of ambulation are routinely and reliably documented by nurses at our institution, and nurses are asked to prompt patients to ambulate within 12 hours of their operation. Opioid utilization data was also gathered from the medical administration record and was quantified as oral, intravenous (IV), and total standard morphine equivalents.

\section{Statistical analysis}

Chi-squared and Fisher's Exact tests were used to compare categorical variables, analysis of variance (ANOVA) was used to compare normally distributed continuous variables, and Kruskal-Wallis tests were used to compare nonnormally distributed continuous variables. Pairwise analyses were performed to compare the SB, LB, and MIX groups. All analyses were performed using Statistical Analysis Systems (SAS) 9.4 (Cary, NC, USA) with threshold for statistical significance defined as $\mathrm{P}<0.05$.

\section{Results}

\section{Cobort characteristics}

Between January 2014 and July 2018, 302 patients met study criteria, of which 34 received SB, 222 received LB, and 46 received MIX. There were no differences in demographic 
characteristics including age, sex, or race among the three cohorts (Table 1). The distributions of specific lobe resected were not statistically different. The procedure times among the three groups were significantly different. Specifically, procedure time in the MIX cohort was significantly shorter than in each of the other two cohorts. There was no statistical difference between procedure time in the SB cohort compared to the LB cohort. Other than the percentage of patients with chronic kidney disease (CKD), there was no difference among patient comorbidities within the three cohorts. Of note, 19 patients who received SB INB and 21 patients who received LB INB were included previously in our pilot study (11).

\section{Primary outcomes}

Median LOS was nearly a full day shorter in the LB cohort than in the SB cohort $(-22 \mathrm{~h}, \mathrm{P}=0.01)$. Median LOS of the MIX cohort was also shorter than that of the SB cohort $(-8 \mathrm{~h})$ though the difference was not statistically significant $(\mathrm{P}=0.10)$, as shown in Figure 1. Clinical outcomes and pairwise comparisons can be found in Tables 2,3, respectively. Median total morphine equivalent utilization was nearly $25 \%$ lower in the MIX cohort than in the LB cohort (-7.1 mg, $\mathrm{P}=0.02)$. Additionally, the median IV morphine equivalent utilization of the MIX group was just $47.4 \%$ of that of the SB cohort $(-10.0 \mathrm{mg}, \mathrm{P}=0.03)$. Oral morphine equivalent use was also $33.3 \%$ lower in the MIX cohort than in the LB cohort $(-5.0 \mathrm{mg}, \mathrm{P}=0.04)$.

\section{Secondary outcomes}

Time to ambulation postoperatively was shortest in the MIX cohort $(8.4 \mathrm{~h})$ followed by the LB cohort $(10.1 \mathrm{~h})$ and the SB cohort (13.7 h), though these differences were not statistically significant $(\mathrm{P}=0.12)$. Median post-operative pain scores and total number of ED readmissions were also not significantly different among the three cohorts $(\mathrm{P}=0.50$ and 0.46 respectively).

\section{Discussion}

This is the largest study of any kind comparing INB with $S B$ versus $L B$ among patients who underwent VATS pulmonary resection, and it is the first study to evaluate the efficacy of a SB-LB mixed solution in INB for postoperative thoracic pain control. Our findings of a reduced LOS in those receiving LB INB are consistent with our earlier pilot study which included a mix of VATS lung and esophageal procedures, and the reduced morphine equivalent usage in the MIX group suggests an even more effective agent for pain control (11).

Patients receiving LB INB left the hospital nearly a full day earlier than those receiving SB INB. This is a critical finding given that each day spent in the hospital is associated with increased risk of hospital-associated infection (15). The reduction in LOS also supports the cost-effectiveness of LB $\mathrm{INB}$, given that the national average inpatient hospital stay costs over \$2,500 per day (16). This argues in favor of LB as a cost-effective option, despite its cost of about $\$ 300$ per vial.

Of the handful of other small studies that compared INB with SB versus LB in VATS patients, some suggested reduced opioid requirements in the $L B$ population $(8-10,12)$, whereas one claimed no difference at all in opioid use or total LOS (13). All but two of these studies evaluated a heterogeneous sample of VATS operations that also included wedge resection (9,11-13), sympathectomy, and mediastinal procedures. In addition to including a heterogeneous population of lung resections, a recent small randomized trial consists of nearly entirely robotic resections (13). Our study is not only larger than these studies, but it addresses bias attributed to the heterogeneity of previous studies by focusing strictly on a cohort of VATS lobectomies.

This is also the first study to examine the efficacy of a LB-standard release bupivacaine mixed solution for INB. Interestingly, the patients receiving the novel MIX solution used fewer total morphine equivalents when compared to the patients receiving LB. Also, the finding that there was no difference in post-operative pain scores or times to ambulation across the three cohorts implies that patients in the MIX group required less opioid to achieve these same results. We believe these findings support the hypothesized advantage of combining standard release bupivacaine and $\mathrm{LB}$.

There is an overall difference in the procedure times among the three groups. However, between the two groups with statistically different LOS, SB and LB, the procedure times were not statistically different. Also, of note, there was a difference among the rates of patients with CKD. The largest proportion of patients with this condition were in the SB group, and while this alone may be unlikely to be the sole difference in LOS among the patients studied, it does represent a possible confounding variable. However, bupivacaine is excreted by the kidney, so a small risk 
Table 1 Cohort demographic and clinical characteristic

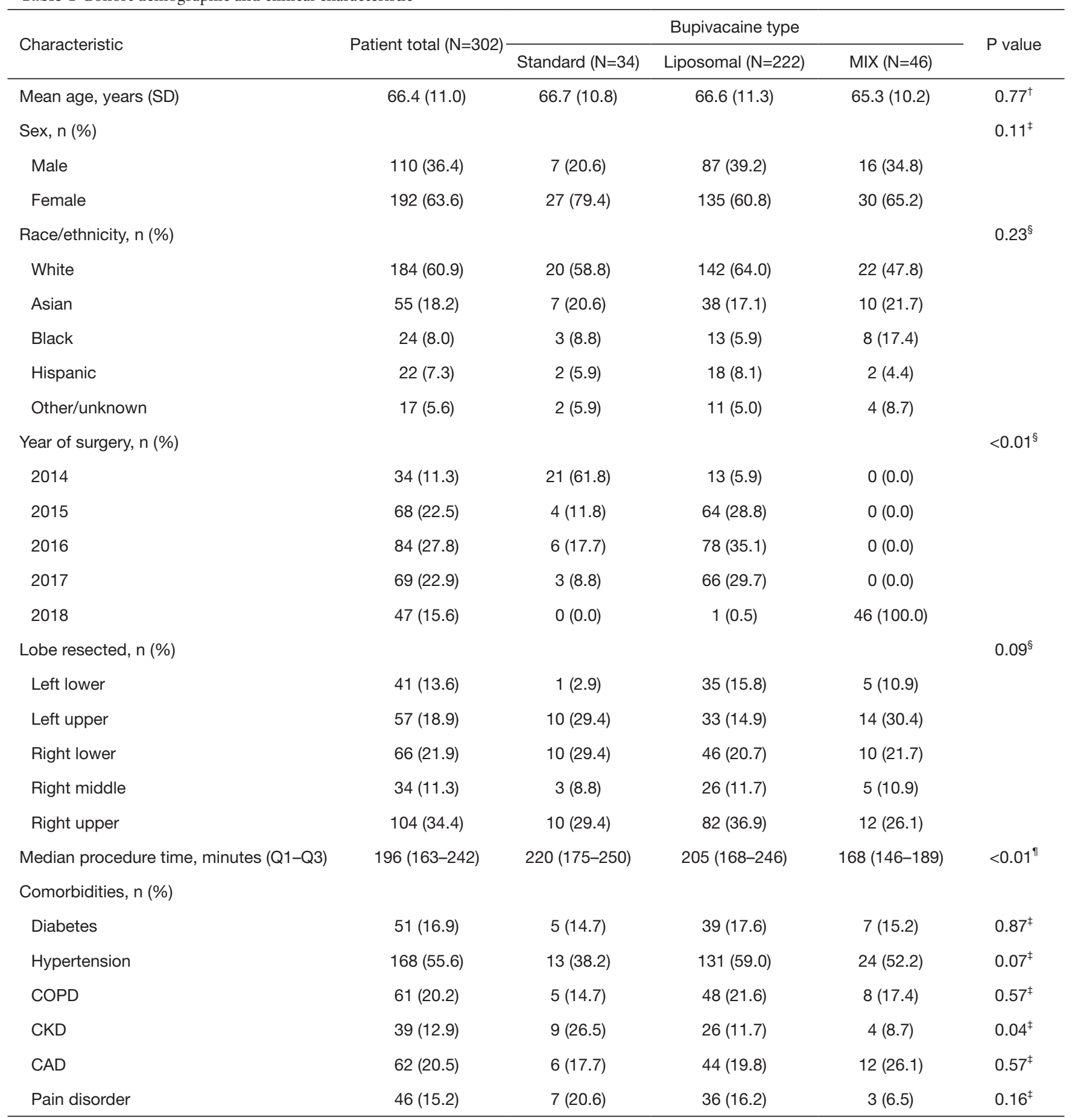

${ }^{\dagger}$, one-way analysis of variance; ${ }^{\ddagger}$, chi-square test; ${ }^{\S}$, Fisher's exact test; ", Kruskal-Wallis one-way analysis of variance. MIX, mix of standard and liposomal bupivacaine; SD, standard deviation; Q1-Q3, quartile 1-quartile 3; COPD, chronic obstructive pulmonary disease; CKD, chronic kidney disease; CAD, coronary artery disease. 
associated with using this analgesic agent is prolonged absorption in the tissue, which theoretically could increase the local analgesic effect of bupivacaine and thus decrease opiate utilization in the SB group. All other patient characteristics and comorbidities, however, including

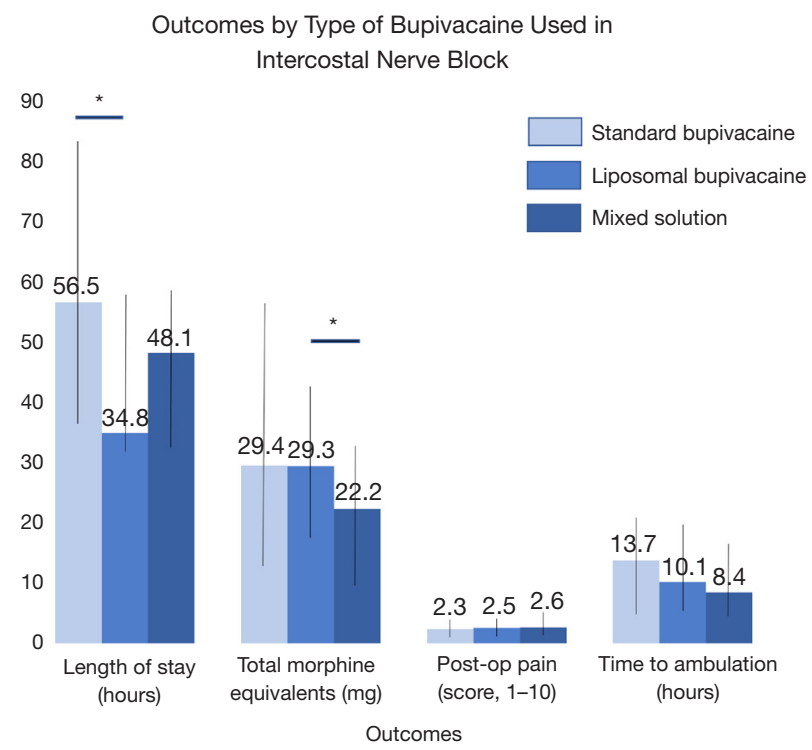

Figure 1 Outcomes by type of bupivacaine used in intercostal nerve blockade. Vertical lines depict interquartile range. *, $\mathrm{P}<0.05$. presence of a prior pain disorder, were not significantly different among the cohorts studied.

While our study is limited by its retrospective design, the historical cohort-based approach minimizes selection bias and inter-group variability because the changes in INB solution utilized occurred uniformly within an otherwise stable practice. The study population incorporates patients treated prior to the implementation of ERAS pathways at our institution, so we believe the differences noted are truly related to the type of bupivacaine used. Still, given the study design, it is impossible to rule out all potential confounders that may have emerged over the time period of the study. An important limitation of our study is that while our sample size of 222 patients receiving LB-based INBs was large, the SB and MIX groups were much smaller. There was no statistically significant difference in LOS between SB and MIX cohorts despite fairly prominent quantitative differences. Similarly, total morphine equivalent use between SB and MIX groups were not significantly different, though IV equivalents were reduced in the MIX group compared to SB. It would be interesting to see if these differences would be statistically significant with larger sample sizes in these groups.

In general, patients receiving LB-based INB had improved post-operative pain control as evidenced by the reduced LOS and decreased opioid utilization. While this

Table 2 Clinical outcomes

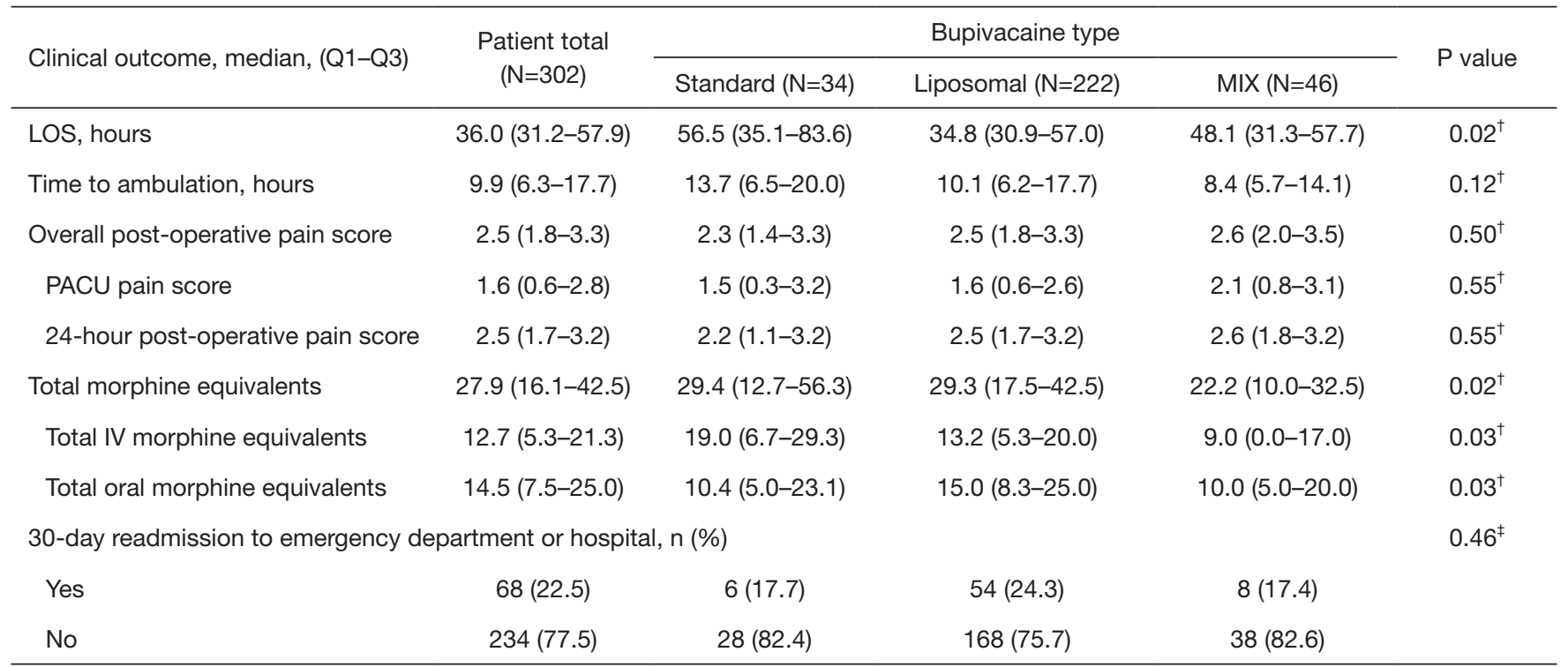

${ }^{\dagger}$, Kruskal-Wallis test; ${ }^{\ddagger}$, chi-square test. Q1-Q3, quartile 1-quartile 3; MIX, mix of standard and liposomal bupivacaine; LOS, length of stay; PACU, post-anesthesia care unit; IV, intravenous. 
Table 3 Pairwise comparisons

\begin{tabular}{|c|c|c|c|c|c|c|}
\hline Clinical outcome, median (Q1-Q3) & \multicolumn{3}{|c|}{ Bupivacaine type } & $\begin{array}{c}\text { Standard vs. } \\
\text { liposomal, P value }\end{array}$ & $\begin{array}{l}\text { Standard vs. } \\
\text { MIX, P value }\end{array}$ & $\begin{array}{l}\text { Liposomal vs. } \\
\text { MIX, P value }\end{array}$ \\
\hline LOS, hours & $56.5(35.1-83.6)$ & $34.8(30.9-57.0)$ & $48.1(31.3-57.7)$ & 0.01 & 0.1 & 0.86 \\
\hline Time to ambulation, hours & $13.7(6.5-20.0)$ & $10.1(6.2-17.7)$ & $8.4(5.7-14.1)$ & 0.48 & 0.13 & 0.27 \\
\hline Average post-operative pain score & $2.3(1.4-3.3)$ & $2.5(1.8-3.3)$ & $2.6(2.0-3.5)$ & 0.56 & 0.5 & 0.92 \\
\hline Total IV morphine equivalents & $19.0(6.7-29.3)$ & $13.2(5.3-20.0)$ & $9.0(0.0-17.0)$ & 0.26 & 0.03 & 0.11 \\
\hline Total oral morphine equivalents & $10.4(5.0-23.1)$ & $15.0(8.3-25.0)$ & $10.0(5.0-20.0)$ & 0.32 & 0.95 & 0.04 \\
\hline
\end{tabular}

Pairwise comparisons with Dwass, Steel, Critchlow-Fligner method. Q1-Q3, quartile 1-quartile 3; MIX, mix of standard and liposomal bupivacaine; LOS, length of stay; IV, intravenous.

method of pain control has clear benefit in terms of cost savings, it also has potential implications for long-term survival. Several studies have shown higher long-term mortality rates among pulmonary resection patients who develop pneumonia post-operatively (17-21). Given the association between post-operative pain and development of pneumonia, this improved post-operative pain control suggests a potential survival advantage for pulmonary resection patients receiving LB- based INB (1).

This study provides compelling evidence to support the use of LB-based INB rather than SB INB for postoperative pain control in patients undergoing VATS lobectomy. Large randomized controlled trials among uniform case populations will be the next step in evaluating this method of postoperative thoracic analgesia against other modes of local and regional analgesia. Ultimately, these effects of INBs may lead to more comfortable post-operative recoveries for patients, considerable cost-savings for hospital systems, and reduced post-operative infections $(1,16)$.

\section{Acknowledgments}

We thank Pamela Derish, MA (Scientific Publications Manager of the UCSF Department of Surgery) and Mary Anne Armstrong, MA (Director, Division of Research Biostatistical Consulting Unit) for sharing their expertise in the editing of this manuscript.

Funding: This work was supported by the Kaiser Permanente Northern California Graduate Medical Education Research Fund and Kaiser Permanente Northern California Community Benefit Program. The funding source was not involved in study design, data collection, analysis/interpretation of data, writing of the report, or decision to submit the article for publication.

\section{Footnote}

Reporting Checklist: The authors have completed the TREND reporting checklist. Available at https://jtd. amegroups.com/article/view/10.21037/jtd-21-1583/rc

Data Sharing Statement: Available at https://jtd.amegroups. com/article/view/10.21037/jtd-21-1583/dss

Peer Review File: Available at https://jtd.amegroups.com/ article/view/10.21037/jtd-21-1583/prf

Conflicts of Interest: All authors have completed the ICMJE uniform disclosure form (available at https://jtd.amegroups. com/article/view/10.21037/jtd-21-1583/coif). The authors have no conflicts of interest to declare.

Ethical Statement: The authors are accountable for all aspects of the work in ensuring that questions related to the accuracy or integrity of any part of the work are appropriately investigated and resolved. The study was conducted in accordance with the Declaration of Helsinki (as revised in 2013). The study was approved by Institutional Review Board of Kaiser Permanente Northern California (IRB: CN-15-2502-H_06) and individual consent for this retrospective analysis was waived.

Open Access Statement: This is an Open Access article distributed in accordance with the Creative Commons 
Attribution-NonCommercial-NoDerivs 4.0 International License (CC BY-NC-ND 4.0), which permits the noncommercial replication and distribution of the article with the strict proviso that no changes or edits are made and the original work is properly cited (including links to both the formal publication through the relevant DOI and the license). See: https://creativecommons.org/licenses/by-nc-nd/4.0/.

\section{References}

1. Özcan PE, Şentürk E. Pneumonia after thoracic surgery. Postoper Care Thorac Surg 2017;207-17.

2. Das-Neves-Pereira JC, Bagan P, Coimbra-Israel AP, et al. Fast-track rehabilitation for lung cancer lobectomy: a fiveyear experience. Eur J Cardiothorac Surg 2009;36:383-91; discussion 391-2.

3. Kalisch BJ, Lee S, Dabney BW. Outcomes of inpatient mobilization: a literature review. J Clin Nurs 2014;23:1486-501.

4. Kilic A, Schuchert MJ, Landreneau JR, et al. The impact of length of hospitalization following surgical resection of stage I non-small cell lung cancer on long-term survival. J Clin Oncol 2009;27:7584.

5. Rice DC, Cata JP, Mena GE, et al. Posterior intercostal nerve block with liposomal bupivacaine: an alternative to thoracic epidural analgesia. Ann Thorac Surg 2015;99:1953-60.

6. Khalil KG, Boutrous ML, Irani AD, et al. Operative intercostal nerve blocks with long-acting bupivacaine liposome for pain control after thoracotomy. Ann Thorac Surg 2015;100:2013-8.

7. Medina M, Foiles SR, Francois M, et al. Comparison of cost and outcomes in patients receiving thoracic epidural versus liposomal bupivacaine for video-assisted thoracoscopic pulmonary resection. Am J Surg 2019;217:520-4.

8. Parascandola SA, Ibañez J, Keir G, et al. Liposomal bupivacaine versus bupivacaine/epinephrine after videoassisted thoracoscopic wedge resection + . Interact Cardiovasc Thorac Surg 2017;24:925-30.

9. Kelley TM Jr, Bailey DW, Sparks P, et al. Intercostal nerve blockade with exparel@ results in lower opioid usage during the first 24 hours after video-assisted thorascopic surgery. Am Surg 2018;84:1433-8.

10. Louis SG, King C, Baral P, et al. Liposomal bupivacaine enhances the pain-control benefits of uniportal thoracoscopic lobectomy. Ann Thorac Surg 2019;108:1514-8.

11. Dominguez DA, Ely S, Bach C, et al. Impact of intercostal nerve blocks using liposomal versus standard bupivacaine on length of stay in minimally invasive thoracic surgery patients. J Thorac Dis 2018;10:6873-9.

12. Balocco AL, Van Zundert PGE, Gan SS, et al. Extended release bupivacaine formulations for postoperative analgesia: an update. Curr Opin Anaesthesiol 2018;31:636-42.

13. Weksler B, Sullivan JL, Schumacher LY. Randomized trial of bupivacaine with epinephrine versus bupivacaine liposome suspension in patients undergoing minimally invasive lung resection. J Thorac Cardiovasc Surg 2021;161:1652-61.

14. Kharitonov V. A review of the compatibility of liposome bupivacaine with other drug products and commonly used implant materials. Postgrad Med 2014;126:129-38.

15. Hassan M, Tuckman HP, Patrick RH, et al. Hospital length of stay and probability of acquiring infection. Int J Pharm Healthc Mark 2010;4:324-38.

16. Martin JA, Hamilton BE, Osterman MJK, et al. Births: final data for 2018. Natl Vital Stat Rep 2019;68:1-47.

17. Rueth NM, Parsons HM, Habermann EB, et al. The long-term impact of surgical complications after resection of stage I nonsmall cell lung cancer: a population-based survival analysis. Ann Surg 2011;254:368-74.

18. Simonsen DF, Søgaard M, Bozi I, et al. Risk factors for postoperative pneumonia after lung cancer surgery and impact of pneumonia on survival. Respir Med 2015;109:1340-6.

19. Fernandez FG, Kosinski AS, Furnary AP, et al. Differential effects of operative complications on survival after surgery for primary lung cancer. J Thorac Cardiovasc Surg 2018;155:1254-1264.e1.

20. Bouabdallah I, Pauly V, Viprey M, et al. Unplanned readmission and survival after video-assisted thoracic surgery and open thoracotomy in patients with non-smallcell lung cancer: a 12-month nationwide cohort study. Eur J Cardiothorac Surg 2021;59:987-95.

21. Ploeg AJ, Kappetein AP, van Tongeren RB, et al. Factors associated with perioperative complications and long-term results after pulmonary resection for primary carcinoma of the lung. Eur J Cardiothorac Surg 2003;23:26-9.

Cite this article as: Banks K, Ely S, Hsu DS, Dominguez DA, Gologorsky RC, Wei J, Maxim C, Ashiku SK, Patel AR, Velotta JB. Intercostal nerve blockade with liposomal bupivacaine reduces length of stay after video assisted thoracic surgery (VATS) lobectomy. J Thorac Dis 2022;14(1):18-25. doi: $10.21037 /$ jtd-21-1583 